Revue interdisciplinaire d'Humanités

$14 \mid 2018$

Plurilinguismes en construction

\title{
Isabelle Graci, Marielle Rispail, Marine Totozani, L'Arc-en-ciel de nos langues. Jalons pour une école plurilingue
}

Nicolas Caussé

\section{CpenEdition}

Journals

Édition électronique

URL : http://journals.openedition.org/essais/396

DOI : $10.4000 /$ essais.396

ISSN : 2276-0970

Éditeur

École doctorale Montaigne Humanités

\section{Édition imprimée}

Date de publication : 1 juin 2018

Pagination : 199-200

ISBN : 979-10-97024-06-2

ISSN : 2417-4211

Référence électronique

Nicolas Caussé, «Isabelle Graci, Marielle Rispail, Marine Totozani, L'Arc-en-ciel de nos langues. Jalons pour une école plurilingue », Essais [En ligne], 14 | 2018, mis en ligne le 01 décembre 2019, consulté le 24 septembre 2020. URL : http://journals.openedition.org/essais/396 ; DOI : https://doi.org/10.4000/ essais.396 


\section{Comptes rendus}

Isabelle Graci, Marielle Rispail, Marine Totozani, L'Arc-en-ciel de nos
langues. Jalons pour une école plurilingue, Paris, L'Harmattan, 2017, 292 p.

Le constat d'une inadéquation entre la formation des enseignant.e.s et la réalité des classes comme des espaces plurilingues et pluriculturels est à l'origine de l'ouvrage, L'arc-en-ciel de nos langues, dirigé par Isabelle Graci, enseignante de français langue seconde et coordinatrice du Dispositif d'Accueil et de Scolarisation des Élèves Allophones de la Loire, Marielle Rispail et Marine Totozani, enseignantes-chercheures à l'Université Jean Monnet Saint-Étienne. Il s'adresse aux enseignant.e.s et formateur/trice.s intéressé.e.s, intrigué.e.s par la présence d'habitudes linguistiques et culturelles différentes dans leur classe. Il est le fruit d'un travail collectif mené pendant trois ans à Saint-Étienne.

Comment faire pour que la pluralité linguistique et culturelle qu'accueillent nos écoles aujourd'hui devienne une richesse qui profite à tou.te.s les élèves? Cette question fut le point de départ d'une recherche-action-formation, menée par les trois coordinatrices de l'équipe et de l'ouvrage. Elles ont accompagné le déroulement de ce projet avec une quinzaine d'enseignant.e.s, depuis sa conception jusqu'à la rédaction de cet ouvrage qui a pour but de " proposer des outils de formation pour faire au plurilinguisme et au pluriculturalisme une place de choix dans nos classes et ainsi de faire évoluer les représentations des enseignants du $1^{\text {er }}$ et $2^{\text {nd }}$ degrés sur l'intégration des élèves allophones en classe ordinaire. " (p. 12). Il est en effet " devenu urgent de former les enseignants des classes ordinaires à des approches pédagogiques prenant en compte les allophones débutants. » (p. 41). Ce volume, appuyé sur des expériences de terrain récoltées dans les classes, a pour ambition d'apporter des pistes pédagogiques allant dans ce sens. Il est composé de trois parties précédées d'un entretien savoureux avec S. Origlio. Cet ancien principal de collège, qui a donné lieu à de nombreux reportages médiatiques et sujets d'ouvrages pédagogiques, pour son travail novateur dans son collège d'une ZEP grenobloise, a accepté de partager son expérience et ses souvenirs. 
La première partie offre quelques éclairages théoriques sur des questions autour du plurilinguisme que l'on se pose en tant qu'enseignants. Le discours tenu est volontairement accessible aux non-linguistes curieux, qui pourront s'approprier avec aisance les quelques concepts clefs du plurilinguisme. Cette première partie veut faire un tour d'horizon de diverses questions liées à la rencontre des langues dans la classe : en commençant par un aperçu de quelques préjugés ambiants pour les déconstruire peu à peu et faire affleurer de nouvelles questions.

La deuxième partie compile des fiches pédagogiques issues d'activités ponctuelles en classe, qui peuvent servir de base pour travailler concrètement selon l'âge des enfants mais aussi pour réfléchir en équipe sur les pratiques ou évitements didactiques liés à la pluralité des langues qui désarçonnent souvent les enseignants au lieu de les stimuler.

La dernière partie livre quelques projets déroulés dans le temps, mis en place avec passion et conviction par les participant.e.s à cette recherche. Ils montrent que tout est possible, qu'on peut tirer parti des contacts des langues et des cultures de nos élèves, au lieu de les voir comme un obstacle : on débouche sur de nouvelles compétences, tout est à créer, le champ des possibles est illimité.

La modestie des acteurs de l'ouvrage, qui met en avant le travail de terrain des enseignant.e.s ne doit pas masquer qu'il s'agit d'une réflexion assumée, revendicatrice d'une volonté de communication entre les langues et cultures grâce au développement des compétences plurilingues et métalinguistiques communes. Réflexion qui semble visionnaire, difficile à partager peut-être pour celles et ceux qui aspirent à une société basée sur des concepts au singulier, alors que les acteurs et auteur.e.s ici appellent à les mettre au pluriel.

Cet ouvrage n'est pas qu'un engagement idéalisé de chercheur.e.s et enseignant.e.s prônant un vivre ensemble utopique mais un recueil d'outils didactiques concrets permettant de mettre en lumières des trésors linguistiques et culturels enfouis sous des préjugés d'ignorance. Rien n'est plus à l'encontre des propos tenus dans cette ouvrage que la revendication de l'hégémonie des cultures dites " fortes " parce qu'isolées les unes des autres. On nous propose une approche innovante dont il reste sans doute à évaluer les effets, pour en déterminer l'efficacité sur l'apprentissage d'une nouvelle langue, ici le français pour des enfants allophones, et leur intégration dans une nouvelle société. Peut-être que ce n'est pas dans "l'efficacité » didactique que l'on pourra juger, sur le long temps, la démarche, mais en voyant si elle œuvre pour la construction d'une société plus juste, plus tolérante et plus fraternelle en dessinant les contours d'un modèle alternatif qui permettrait à l'école d'être le ferment de l'intégration sociale, à la fois des enfants, des parents et des familles.

Nicolas Caussé

CELEC (EA 3069)

Université Lyon UJM Saint-Étienne n.causse.eh@gmail.com 